\title{
COMBINED SUPRA/INFRATENTORIAL APPROACH TO TENTORIAL MENINGIOMAS
}

\author{
Igor de Castro', Daniel de Holanda Christoph², José Alberto Landeiro³
}

\begin{abstract}
In spite of significant advancements in imaging technology, monitoring, and microsurgical techniques, complete and safe removal of tentorial meningiomas remains a challenge for most neurosurgeons. Classifications of tentorial meningiomas are revised. The combined supra/infratentorial approach to resects tentorial meningioma is discussed. This approach provides a wider exposure of the supra/infratentorial region with less brain retraction. With this approach the occipital lobe and the cerebellum are exposed along the tentorium. Two illustrative cases are presented. The patients were studied with computerized tomography, magnetic resonance and angiography. The anatomy of the transverse sinus and the confluence of the sinus could be appreciated with these studies. The operative technique is described stepwise. Emphasis is placed on pre-operative evaluation and surgical technique, leading to a total surgical removal of the lesion with margins of safety. The goal of surgical treatment of tentorial meningiomas is their complete and safe removal. With this unique approach we sought to confirm that it offers a safe means of resection not only the neoplasm but also the infiltrated dura.
\end{abstract}

KEY WORDS: tentorial meningioma, surgical approach, supra/infratentorial, combined craniotomy.

\begin{abstract}
Abordagem combinada supra e infratentorial aos meningiomas tentoriais
RESUMO - Apesar dos significativos avanços na tecnologia de imagens, nas técnicas de monitorização e microcirúrgicas, a ressecção completa e segura dos meningiomas tentoriais permanece um desafio para maioria dos neurocirurgiões. A abordagem supra e infra-tentorial proporciona ampla exposição das regiões supra e infratentoriais diminuindo a retração cerebral. Com esse tipo de abordagem o lobo occiptal e o cerebelo são expostos ao longo da superficie tentorial. Dois casos ilustrativos são apresentados. Os pacientes foram avaliados com tomografia computadorizada, ressonância magnética e angiografia, o que permitiu estudar a anatomia do seio transverso, a confluência e dominancia dos seios. O objetivo do tratamento cirúrgico dos meningiomas tentoriais é a remoção completa e segura. A associação das imagens, o acesso combinado e a técnica microcirúrgica permitem a remoção cirúrgica total deste tipo de lesão e do implante dural com margens de segurança.
\end{abstract}

PALAVRAS-CHAVE: meningioma tentorial, craniotomia, supra/infratentorial.

The first report of a tentorial meningioma was in 1833 by Andraal, who discovered a lesion incidentally attached to the tentorium ${ }^{1}$. Tentorial meningiomas account for $2 \%$ to $3 \%$ of all intracranial meningiomas ${ }^{2-5}$. In the Cushing and Eisenhard's series of 295 intracranal meningiomas, 11 tumors (3.7\%) were attached to the tentorium ${ }^{6}$. Olivecrona ${ }^{7}$ series included 21 tentorial meningiomas representing $2.5 \%$ of all of their intracranial meningiomas. He found in his series $52 \%$ of these lesions above the tentorium and $48 \%$ below. The transverse sinus was invaded in $52 \%$. In a such way the first attempt to classify the tentorial meningioma was made by him. To discuss the surgical management of tentorial me- ningiomas appropriately, one must be based on their site of origin. With this finality many authors proposed different classifications of the posterior fossa meningiomas ${ }^{1,8,9}$. In the era pre computerized tomography (CT), the majority of the authors agreed that the tentorium was the most common site of the posterior fossa meningioma ${ }^{10}$. With the advent of CT in the early 1970s, numerous authors have attempted to lend order to these lesions by assingning classification ${ }^{9,11-15}$. According with Harrison and Al-Mefty ${ }^{16}$ we find the scheme proposed by Yasargil was the one of the most beneficial ${ }^{15,16}$. The choice of operative approach depends mainly on the site of the lesion. The size of the lesion will dictate the

Hospital da Força Aérea do Galeão, Rio de Janeiro RJ, Brasil, (HAFG); Hospital Universitário Antonio Pedro da Universidade Federal Fluminence, Niterói RJ, Brasil (HUAP); ' $A$ sssistente de Neurocirurgia do HFAG; ${ }^{2}$ Estudante da Graduação da Faculdade de Medicina, da Universidade Federal do Rio de Janeiro (UFRJ) Rio de Janeiro RJ, Brasil; ${ }^{3}$ Serviço de Neurocirurgia do HFAG e HUAP

Received 23 June 2004. Accepted 27 September 2004.

Dr. José Alberto Landeiro - Avenida Monsenhor Ascâneo 591/202 - 22621-060 Rio de Janeiro RJ - Brasil. 
size of the craniotomy. The majority of the purely tentorial tumors can be removed by the author proposed approach. The combined supra/infratentorial approach is a modified adaptation of the approach described by Ziyal et al. for pineal tumors ${ }^{17}$. In his publication he mentioned a successful removal of 4 tentorial meningioma, but differing from our approach, a more flap craniotomy and sinus ligation were used. The experience gained with the posterior fossa craniotomy stimulated the authors to perform a single flap craniotomy involving the supra/infratentorial compartments to remove tentorial meningiomas ${ }^{18}$. The proposed approach proves to be safe and easy to perform after appropriate training with the high power surgical drill and craniotomy. There is no need for two or more flap craniotomies or subocciptal craniectomies. The preoperative evaluation and the surgical approach itself will be described in detail.

\section{PREOPERATIVE EVALUATION}

In all patients with tentorial meningiomas, a contrastenhanced CT scan and a magnetic resonance (MRI) of the brain should be ordered. The CT scan in axial and coronal views should be carefully evaluated to see the relations of the lesion with the falx and tentorium. The CT images still provide superior bone detail and are invaluable where tumors invade bones. The MRI is more precise on revealing information about tumor localization, extension and its relations. Special attention should be given to where the tumor expands mostly into the two compartments. In fact with, MR and MR angiography (MRA) the size, dominance and collateralization of the transverse sinuses can be recognized. This factor is essential for this kind of approach. We should obtain all possible possible about the transverse sinus status. If infiltration is present, it should be quantified.

Cerebral angiography is sometimes necessary to obtain additional information about the arterial and venous system. Using the four-vessels angiography we are able to delineate the vascularity of the lesion and its relationship to the various arteries and veins in this area. The circulation supplying the tumor is carefully analyzed in order to plan both endovascular and surgical procedures. The vein of Galen, the internal cerebral veins and the basal vein of Rosenthal should be studied. As well as the superficial venous system, with the patency of the straight sinus, and the collateralization and enlargement of the normally present sinus should also be analyzed. Preoperative embolization can be used since it is readily available through a very experienced neuroradiologist in the procedure. If the embolization is effective the surgical procedure become easier ${ }^{8}$.

If the sitting position is planned to approach the tentorial meningiomas a complete evaluation of the cervi- cal spine is mandatory. X-rays and MR of the cervical spine should be studied carefully to avoid complications with the positioning.

\section{OPERATIVE TECHNIQUE}

The patient is positioned in a sitting position, which is prefer by the senior author (JAL) to deal with lesions in the posterior fossa for more than fifteen years. With this position, the surgical field remains clean during the whole procedure. The venous pressure is very low and there is less venous bleeding. The main disadvantage of this position is the occurrence of air embolism which is rapidly and precisely diagnosed with the trans-esophageal Doppler. The air can be aspirated from the right atrium with the central lines placed in the correct position preoperatively.

After appropriate preparation and draping, a U-shaped or linear incision is made. The preference of the kind of the incision is dictated by the size of the tumor. Subsequently the skin flaps and muscle are retracted in a single layer. The craniotomy is performed in a single piece. The size of the craniotomy is also dictated by the size of the tumor. We place burr holes above and below the transverse sinus and in a majority of the times, the bone over the sinus is drilled away. For the superior and inferior components of the craniotomy the craniotome can be perfectly used after the dura is dissected from the bone (Fig 1). After the craniotomy, the dura of the occipital lobe and the suboccipital compartment are exposed. The transverse sinus is placed between both compartments. The transverse sinus and its junction with the torcular Herophilli are exposed (Fig 2).

The suboccipital dura is opened in a transverse triangular fashion just inferior to the transverse sinus. This type of opening facilitates the subsequently water-tight closure. The cisterna magna is opened to permit the relaxation of the brain. Then, the occipital dura is opened in the same fashion, just superior to the transverse sinus and laterally to the superior sagittal sinus. If the ligation of the sinus is planned, a judicious investigation with MR, MRA and venous phase of angiography should be performed. If the sinus is already occluded with tumor, the sinus can be divided and removed. After the dura opening of the both compartments, the surgeon can appreciate the wide exposure of the tumor along the tentorium (Fig 3). Using microsurgical techniques, the surgeon should start with the evacuation of the tumor content. Gentle traction was exerted on the capsule to separate it from the neighboring vasculonervous structures. In this maneuver, the surgeon must distinguish the vessels and the nerves that lie outside the tumor and have been displaced and stretched from those embedded in the tumor. In the first situation, the vessels and the nerves must be gently separated and protected with sponges. The small arteries that supply the tumor must be identified and not stretched, in order not to tear them at the base of insertion; they should be coagulated and sectioned flush with the tumor. Then the tumor can be 


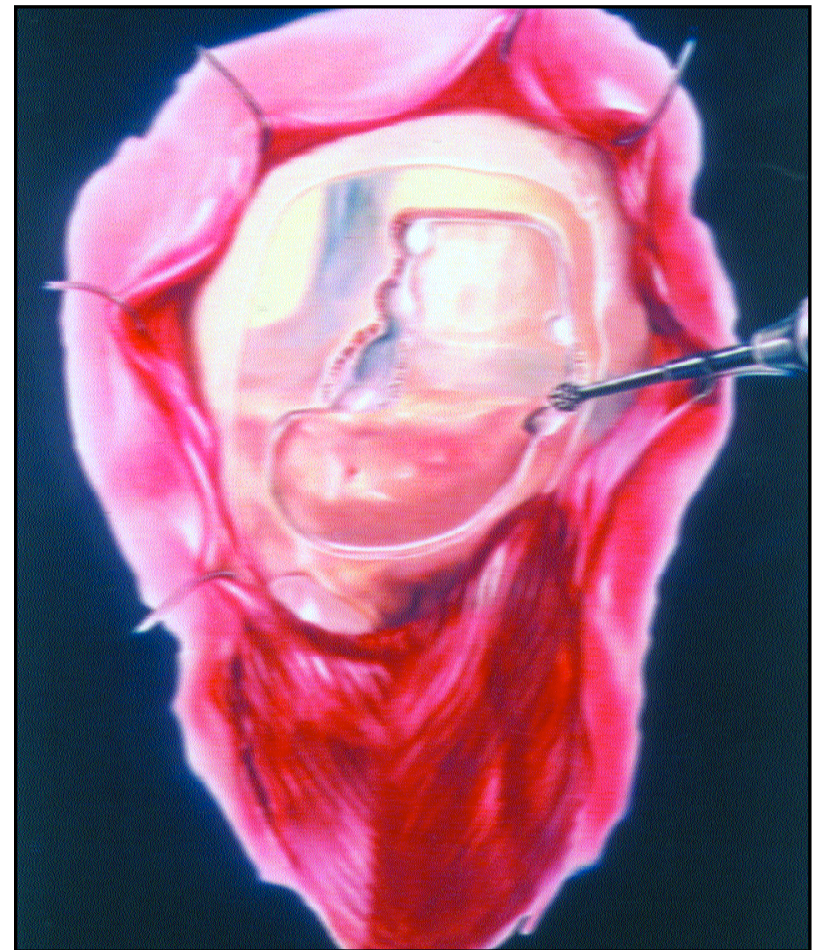

Fig 1. The craniotomy. The burr holes are placed above and be low the transverse sinus. The craniotome is avoided over the sinus. The drill is used in stead. The tranverse sinus and its junction at the sinuses confluence is appreciated.

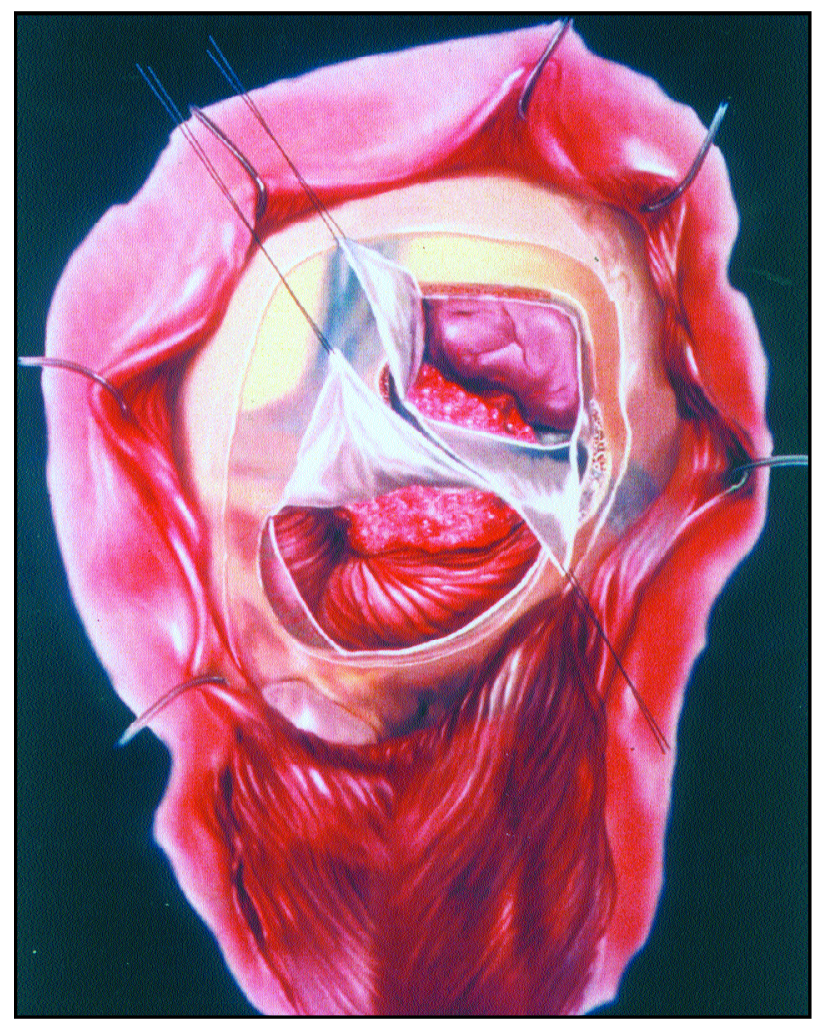

Fig 3. Tumor visualization. After the dura opening the tumor can be seen along the tentorial surface. The tumor can be rea ched from above or below.

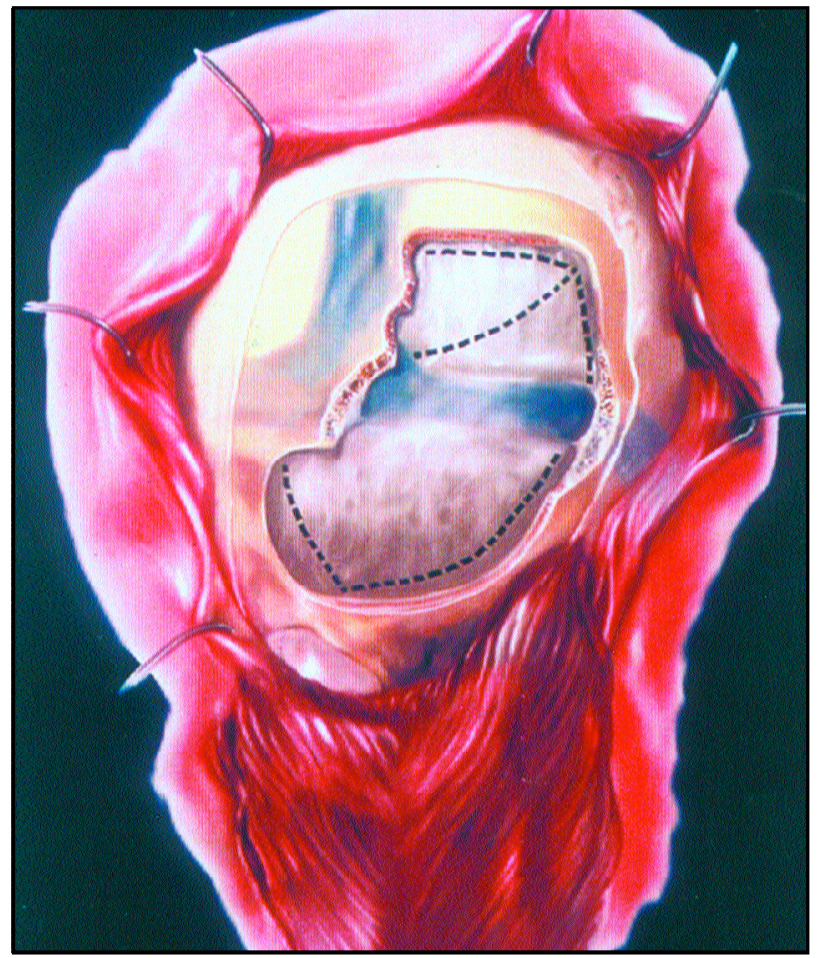

Fig 2. Dural opening. The opening of the dura is tailored in a transverse triangular fashion to facilitate the closure. The occip ital and the sub occipital dura are opened independently. The transverse sinus is not divided and remains in the middle of the two openings.

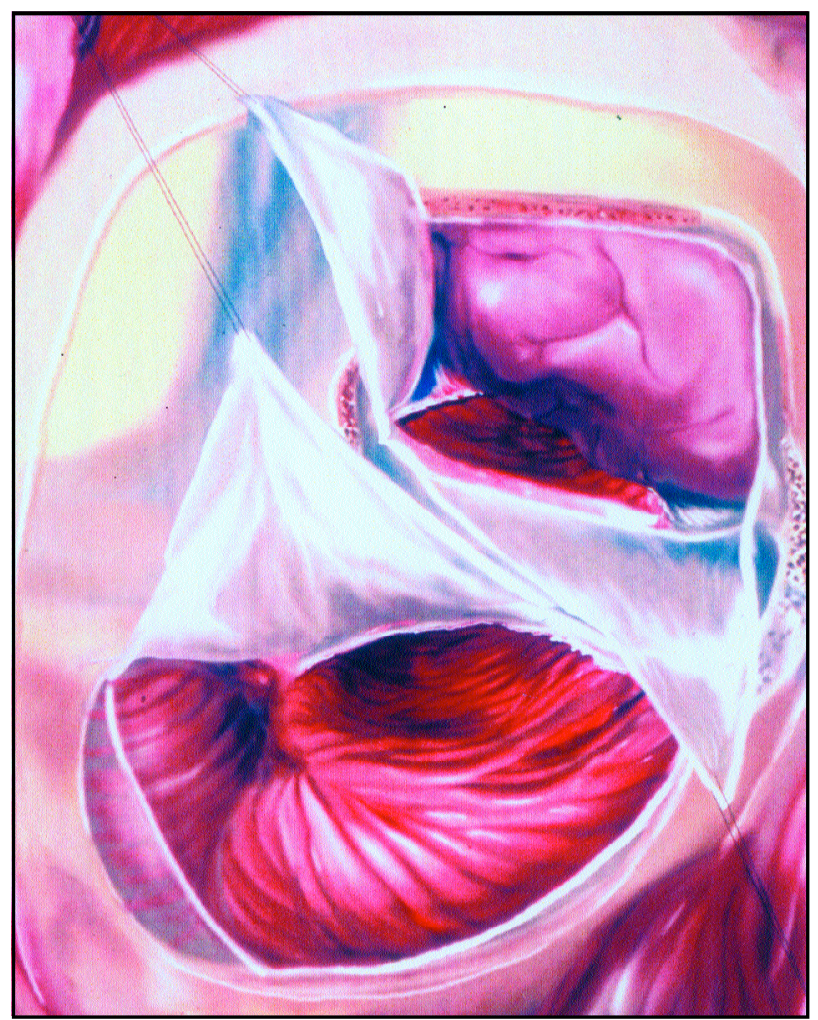

Fig 4. Gross total resection. After the total tumor resection the integrity of the occipital lobe and cerebellar hemisphere is completely preserved as well as the venous sinuses. 


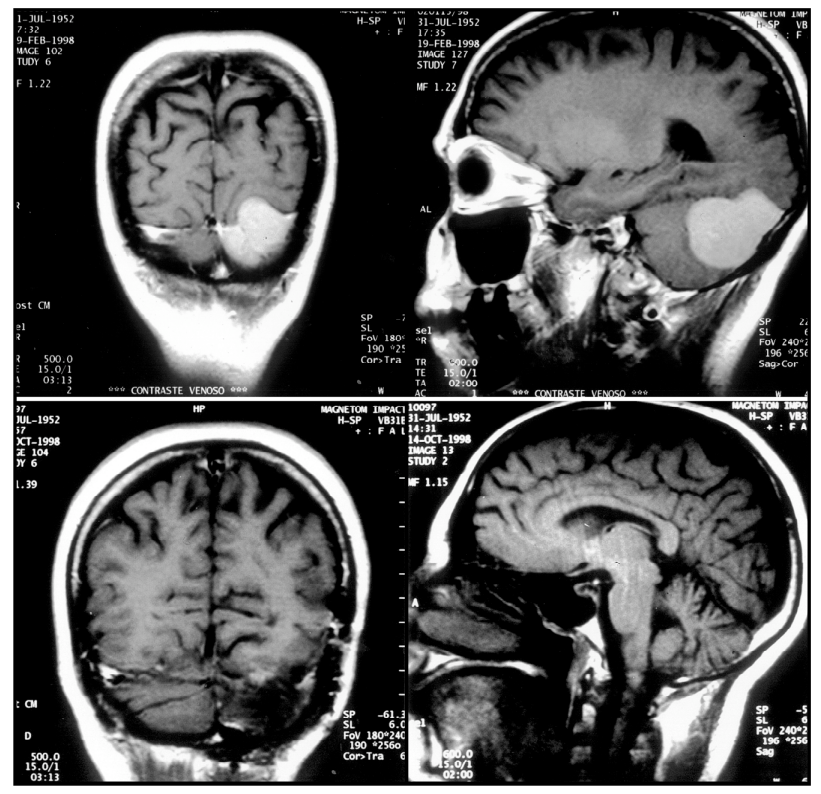

Fig 5. Pre-operative T1-weigthed MRI with contrast in sagital and a coronal projections (A) of tentorial meningioma with both supra and infratentorial extension and postoperative MRI with contrast in sagittal and coronal plane (B) depicting the resection.

radically removed. In cases in which the nerves and the vessels are embedded in the tumor, the use of higher magnification and a piecemeal technique removal around those structures should be applied. Often, in some cases when there is not a plan at all, it is wise to leave a thin layer of the tumor around the arteries and nerves. For those kind of microsurgical dissection, a precise bipolar coagulation technique is essential. Usually the tumor displaces the normal structures and after the debulking, no retraction is really necessary. The use of the Cavitron ultrasonic surgical aspirator (CUSA) has proved to be useful. It is specially valuable to decompress a large tumor with soft consistency. After removal of the tumor, the infiltrated dura must be removed as much as possible. The tentorium is cut just lateral to the straight sinus and toward the tentorial notch. To our point of view with this approach, one can visualize the entire tentorium from above and below, facilitating extremely this dural removal. After the complete removal of the tumor and the tentorium, the occipital lobe and the cerebellum are easily visible (Fig 4). Ilustrative cases are demonstrated in figures 5 and 6 .

\section{DISCUSSION}

As with all meningiomas, tentorial tumors are more common in females in middle- to older age. Tentorial meningiomas are relativily rare lesions which present difficult diagnostic and surgical problems. Despite the fact that tumors in this location represent less than $3 \%$ of all meningiomas, their frequent involvement with dural venous sinuses,

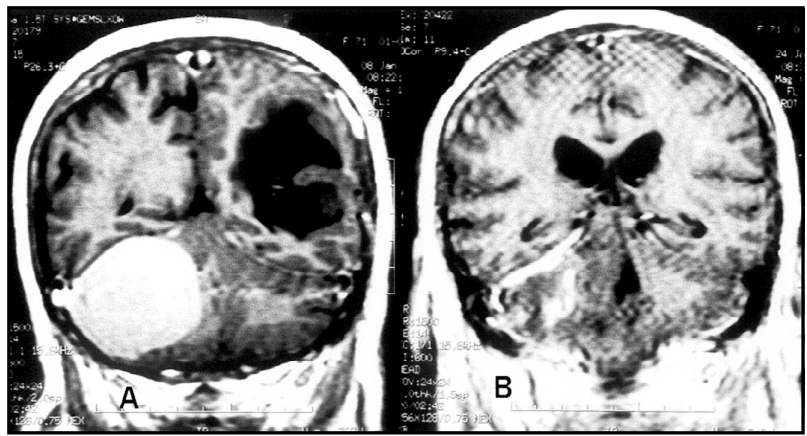

Fig 6. Coronal T1 weighted MRI (A) with a contrast of an old patient with a large tentorial meningioma with supratentorial extension. A immediately postoperative coronal (B) MRI stud ies displaying total resection.

deep venous structures, plus the brainstem and the cranial nerves, they have led to interest far exceeding their rate of occurance ${ }^{16}$.

The choice for the appropriate surgical approach is based upon the site of origin of the lesion. This is of paramount importance in determining the ease of resectability. By careful study of the preoperative diagnostic tests, the surgeon should form a mental image of the location of the tumor and its relationship to major vascular and neural structures.

During the approach, the surgeon must establish close working with the neuro-anesthesiologist, suspending the operation momentarily if any symptom or sign of air embolism is present. The presence of a well positioned central line and trans-esophageal Doppler is mandatory to avoid any complication.

Numerous authors have attempted to lend order to these lesions by assingning classification ${ }^{9,11-15}$. According with Harrison and Al-Mefty, we find the scheme proposed by Yasargil was the one of the most beneficial ${ }^{15,16}$. The schematic classification proposed by Yasargil is very useful. Under his classification, he called T1-T3 the lesions on the inner ring or lesions of the incisura - anterior, lateral and posterior. T4 and T8 are intermediate ring lesions with T8 tumors involving the falcotentorial junction. T5-T7 are lesions on the posterior ring, involving the torcular, transverse sinus, and transversesigmoid junction respectively ${ }^{15}$.

The approach presented by us is more indicated to deal with tumors type 4 and 6 according to this classification. Torcular meningiomas are often addressed separately from other tentorial meningiomas. Tumors of the torcular region require exposure of what has been referred to as all "four quadrants" ${ }^{\prime}$. This includes visualization of the supe- 
rior sagittal sinus, torcular Herophilli, both transverse sinuses, and the occipital sinus proximal and distal to what is involved with tumor. Tumors that arise from the intermediate ring of the tentorium (T4), that do not involve the medial structures and that do not invade the dural venous sinuses are, theoretically, the easiest ones to be managed with the proposed approach.

In the literature one can find that depending on tumor extension supra-, infratentorially, or both, a occipital, suboccipital, or a combined approach may be used.

Where a tumor has only minimal extension into either the supra- or infratentorial compartiment, it can be resected via an approach solely on the side of the sinus with maximum tumor ${ }^{16}$. Originally that the lateral and medial tumors with solely or mainly supratentorial development were approached from above. The approach from below was reserved for meningiomas with subtentorial involvement only. In meningiomas with both supra- and infratentorial growth, a supratentorial flap was combined with a subocciptal craniectomy ${ }^{5}$. With our approach there is no place for craniectomy. However a single bone flap of the two compartiments can be easily performed. We think that even for a single lesion occupying compartment a combined craniotomy can play an important role. Not only as a wide avenue to remove the tumor but also the infiltrated dura can be easily investigated and removed. In our approach to tentorial meningioma the resection of a part of the falx or the tentorium is relatively easy.

We think that, regardless the extension of the tumor, with our proposed approach the tumor and dural resection become easier. The goal to avoid recurrence is to remove the tumor and its implantation ${ }^{19}$. If the tumor can be removed with a $2-\mathrm{cm}$ mar- gin of the tentorium peripheral to the tumor attachment, the so-called Grade 0 proposed by Kinjo et al. can be achieved ${ }^{20}$. If this kind of resection is done we diminish the risk of recurrence almost to zero.

\section{REFERENCES}

1. Yasargil MG, Mortara RW, Curcic M. Meningiomas of the basal posterior cranial fossa In Krayenbhul H (ed): Advances and technical standards in neurosurgery. New York: Springer-Verlag, 1980;7:3-115.

2. Barrows HS, Harter DH. Tentorial meningiomas. J Neurol Neurosurg Psychiatry1962;25:40-44.

3. Castellano F, Ruggiero G. Meningiomas of the posterior fossa. Acta Radiol (Stockh) 1953;104:(Suppl):26-69.

4. McCarty CS, Taylor WF. Intracranial meningiomas: experiences at Mayo Clinic. Neurol Med Chir (Tokyo) 1979;19:569-574.

5. Guidetti B, Ciappetta P, Domenicucci M. Tentorial meningiomas: surg ical experience with 61 cases and long-term results. J Neuro s u rg1988;69: 183-187.

6. Cushing H, Eisenhardt L. Meningiomas. Springfield: Charles C Thomas,1938:506-537.

7. Olivecrona $\mathrm{H}$. The surgical treatment of intracranial tumors In Lohr HH, Luft R, Olivecrona $\mathrm{H}$, et al (eds). Klinik und Behandlung der raumbeengenden intrakraniellen Prozesse. Handbuch der neurochirurgie, Band IV. Berlin: Springer-Verlag, 1967;4:179-181.

8. Sekhar LN, Janetta PJ, Maroon CJ. Tentorial meningiomas: surgical management and results. Neurosurgery 1984;14:268-275.

9. Ciric I, Landau B. Tentorial and posterior cranial fossa meningiomas: operative results and long-term follow-up: experience with twenty six cases. Surg Neurol 1993;39:530-537.

10. Carey JP, Fisher RG, Pelofsky S. Tentorial meningiomas. Surg Neurol 1975;3:41-44

11. Gokalp HZ,Arasil E, Erdogan A, Egemen N, Deda H, Çerçi A. Tentorial meningiomas. Neurosurgery 1995;36:46-51.

12. Malis L. Surgical approaches to tentorial meningiomas. In Wilkins $\mathrm{RH}$ Rengachary SS (eds). Neuro s u rgery update: I. diagnosis, operative technique, and neuro-oncology. New York: McGraw-Hill,1990;399-408.

13. Sen C. Surgical approaches to tentorial meningiomas. In. Wilkins RH, RengacharySS (eds). Neurosurgery. New York: McGraw-Hill,1996;917-924

14. Sugita K, Suzuki Y: Tentorial meningiomas, In Al-Mefty O(ed): Meningiomas. New York: Raven Press, 1991:357-361.

15. Yasargil MG. Microneurosurgery. Stuttgart: Thieme, 1996;4B:134-161.

16. Harrison MJ, Al-Mefty O. Tentorial meningiomas. Clin Neurosurg. 1997;44:451-466.

17. Ziyal IM, Sekhar LN, Salas E, Olan WJ. Combined supra/infratentorial-transsinus approach to large pineal region tumors. J Neurosurg 1998;88:1050-1057.

18. LandeiroJA, Castro ID, Flores MS, Maia OT Jr. Posterior fossa craniotomy: technical report. Arq Neuropsiquiatr 2000;58:169-173.

19. Simpson D. Recurrence of intracranial meningiomas after surgical treatment. J Neurol Neurosurg Psychiatry 1957;20:22-39.

20. Kinjo T, Al-Mefty O, Kanaan I. Grade zero removal of supratentorial convexity meningiomas. Neurosurgery 1993;33:394-399. 